\title{
Seal-mounted cameras detect invertebrate fauna on the underside of an Antarctic ice shelf
}

\author{
Yuuki Watanabe ${ }^{1, *}$, Horst Bornemann ${ }^{2}$, Nikolai Liebsch ${ }^{3,5}$, Joachim Plötz ${ }^{2}$, \\ Katsufumi Sato ${ }^{4,6}$, Yasuhiko Naito ${ }^{4}$, Nobuyuki Miyazaki ${ }^{1}$ \\ ${ }^{1}$ Ocean Research Institute, The University of Tokyo, 1-15-1 Minamidai, Nakano, Tokyo 164-8639, Japan \\ ${ }^{2}$ Alfred-Wegener-Institut für Polar- und Meeresforschung, Postfach 120161, 27515 Bremerhaven, Germany \\ ${ }^{3}$ IFM-Geomar, Düsternbrooker Weg 20, 24105 Kiel, Germany \\ ${ }^{4}$ National Institute of Polar Research, 1-9-10 Kaga, Itabashi, Tokyo 173-8515, Japan \\ ${ }^{5}$ Present address: University of Wales Swansea, Singleton Park, SA2 8PP, Swansea, UK \\ ${ }^{6}$ Present address: International Coastal Research Center, Ocean Research Institute, The University of Tokyo, \\ 2-106-1 Akahama, Otsuchi, Iwate 028-1102, Japan
}

\begin{abstract}
While modern sampling techniques, such as autonomous underwater vehicles, are increasing our knowledge of the fauna beneath Antarctic sea ice of only a few meters in depth, greater sampling difficulties mean that little is known about the marine life underneath Antarctic ice shelves over $100 \mathrm{~m}$ thick. In this study, we present underwater images showing the underside of an Antarctic ice shelf covered by aggregated invertebrate communities, most likely cnidarians and isopods. These images, taken at an average depth of $145 \mathrm{~m}$, were obtained with a digital still camera system attached to Weddell seals Leptonychotes weddellii foraging just beneath the ice shelf. Our observations indicate that, similar to the sea floor, ice shelves serve as an important habitat for a remarkable amount of marine invertebrate fauna in Antarctica.
\end{abstract}

KEY WORDS: Ice shelf · Fauna · Antarctica $\cdot$ Camera $\cdot$ Diving $\cdot$ Weddell seal $\cdot$ Leptonychotes weddellii

\section{INTRODUCTION}

The under-ice environment has long been considered to be an important habitat for marine organisms, but sampling difficulties have previously prevented their direct observation. A recent study using an autonomous underwater vehicle (AUV) revealed that Antarctic krill Euphausia superba are concentrated under Antarctic sea ice that is a few meters thick (Brierley et al. 2002). However, since it is much more difficult to make AUV observations beneath the ice shelves, which can be more than a hundred meters thick, little is known about the marine life there.
The recent development of image recording systems that can be attached to animals has allowed direct observations of diving animals' foraging behavior and of the surrounding environment (Davis et al. 1999, 2003, Ponganis et al. 2000, Hooker et al. 2002, Sato et al. 2002, Watanabe et al. 2003, 2004, Mitani et al. 2004, Takahashi et al. 2004). This development has lead to the concept of using marine predators as autonomous samplers for investigating marine organisms otherwise difficult to observe in their natural environment (Fuiman et al. 2002). We deployed a digital camera system on Weddell seals Leptonychotes weddellii inhabiting an inlet surrounded by the Riiser Larsen Ice Shelf to obtain images of marine organisms that were encountered by the seals during their dives. 


\section{MATERIALS AND METHODS}

Field experiments were conducted from December 4 2003 to January 32004 at Drescher Inlet, Antarctica $\left(72.87^{\circ} \mathrm{S}, 19.43^{\circ} \mathrm{W}\right)$. The inlet is a crack $25 \mathrm{~km}$ long and up to $2 \mathrm{~km}$ wide in the Riiser Larsen Ice Shelf. The depth of the ice shelf surrounding the inlet ranges from $80 \mathrm{~m}$ at the mouth to $160 \mathrm{~m}$ in the inner section of the inlet, and the water depth inside the inlet ranges from 380 to $520 \mathrm{~m}$. Sea ice still covered the inlet during our investigations in the late austral spring.

We attached a camera system (DSL-1000DV, Little Leonardo) to 4 adult female Weddell seals, using the immobilization and deployment techniques described in Bornemann et al. (1998). The camera system consisted of 2 cylindrical housings, each $230 \mathrm{~mm}$ in length and $52 \mathrm{~mm}$ in diameter. One housing contained a flash (guide number 32 ) and the other a color digital still camera (angle of view $45^{\circ}$, effective resolution $510 \times$ 492 pixels), a depth sensor (maximum depth of $1000 \mathrm{~m}$, resolution of $1 \mathrm{~m}$, absolute accuracy of $\pm 5 \mathrm{~m}$ ) and an onboard microcomputer with $64 \mathrm{MB}$ flash memory. It provided depth data at $1 \mathrm{~s}$ intervals, and underwater images at $30 \mathrm{~s}$ intervals below a pressure-sensed depth threshold of $5 \mathrm{~m}$. It weighed $3.4 \mathrm{~kg}$ in air (approximately $1 \%$ of a seal's body mass) and $1.6 \mathrm{~kg}$ in water (for further details, see Watanabe et al. 2003).

A previous study on Weddell seals' diving behavior at Drescher Inlet showed that a mode exists in the distribution of maximum dive depth for dives $\leq 50 \mathrm{~m}$ (Fig. 2 in Plötz et al. 2001). We therefore assumed that the majority of foraging activity occurs during dives with a maximum depth $>50 \mathrm{~m}$ and thus considered all dives $>50 \mathrm{~m}$ to be foraging dives. The criterion of $50 \mathrm{~m}$ was also used in Sato et al. (2002). Means ( \pm 1 SD) are reported.

\section{RESULTS}

A total of 66 dives with a maximum depth $>50 \mathrm{~m}$ were logged for the 4 seals, during recording periods ranging from 8.4 to $38.6 \mathrm{~h}$. During the dives, $2282 \mathrm{un}$ derwater images were obtained. The images allowed us to classify all the 66 dives into 3 groups: 12 dives $(18.2 \%)$ were at the underside of the ice shelf (mean maximum dive depth $152.9 \pm 23.6 \mathrm{~m}$ ) (Fig. 1), 19 dives $(28.8 \%)$ were at the sea bottom (mean maximum dive depth $413.4 \pm 13.4 \mathrm{~m})$ and 35 dives $(53.9 \%)$ were in the pelagial (mean maximum dive depth $117.0 \pm 47.4 \mathrm{~m}$ ). Of the 4 Weddell seals, 2 made dives just below the ice shelf; for one seal these represented 3 out of a total of 23 deep dives $(>50 \mathrm{~m})(13.0 \%)$, for the other 9 out of 15 $(60.0 \%)$. Images (235) taken at a mean depth of $145 \pm$ $18 \mathrm{~m}$ during these particular dives showed the surface structure underneath the ice shelf. Of these 235 images, $203(86.4 \%)$ showed patchy aggregations of invertebrate communities, most likely cnidarians and isopods (Fig. $1 \mathrm{~b}, \mathrm{c}, \mathrm{d}$ ), while the rest of the images $(13.6 \%)$ showed no organisms. A total of 29 images (12.3\%) showed the seals stretching their necks towards the ice shelf surface, possibly to catch prey (Fig. 1e).

\section{DISCUSSION}

To our knowledge, this is the first direct observation of invertebrate fauna on the underside of an Antarctic ice shelf. While rich seafloor fauna in Antarctica have been previously reported (Arntz et al. 1994), our images indicate that Antarctic ice shelves also serve as a substrate for a remarkable amount of invertebrate fauna. Two of the 4 seals dived and foraged just below the ice shelf, suggesting that the area below the ice is also an important habitat for fishes such as Pleuragramma antarcticum, the predominant prey of Weddell seals in the study area (Plötz et al. 2001). This is supported by Fuiman et al. (2002), who observed $P$. antarcticum under an ice shelf in McMurdo Sound, Antarctica, by means of a video camera attached to Weddell seals.

Our new approach of utilizing diving animals to explore otherwise inaccessible regions, such as the underside of ice shelves, is currently limited to descriptive use, primarily because of the relatively low camera resolution (0.25 mega pixels). In addition to capturing higher resolution images, simultaneous ambient data (e.g. salinity, temperature; Hooker \& Boyd 2003) and more precise information on seals' behavior (e.g. swim speed, 3D dive paths; Davis et al. 2003, Mitani et al. 2003, 2004) should allow a more quantitative assessment of the sub-ice shelf invertebrate fauna and the surrounding environment in future studies.

Ice shelves fringe most of the Antarctic continent and constitute $11 \%$ of the total area of Antarctica (Swithinbank 1988). Gradual retreat of ice shelves, punctuated by periods of rapid collapse in response to the regional atmospheric warming over the last few decades (Doake \& Vaughan 1991, Rott et al. 1996, Vaughan \& Doake 1996, Shepherd et al. 2003), could reduce the number and diversity of animals inhabiting these icy substrates and, consequently, may influence the Antarctic marine ecosystem. Therefore, observations such as those made in this study are important in helping to understand the ecology of this unusual ecosystem.

Acknowledgements. We thank all the members of the Polarstern expedition ANT XXI/2, and especially M. Mirhaj, for their assistance. We also thank M. F. Cameron, M. Horning, T. Johnson, M. J. Miller, A. Takahashi, S. Toczko and 2 anonymous referees for helpful comments on the manuscript, 
(a)

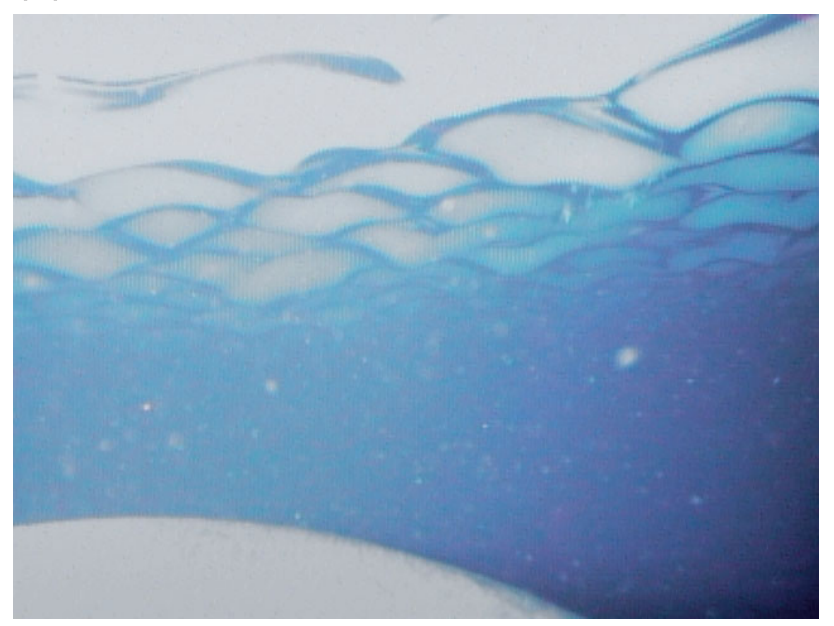

(c)

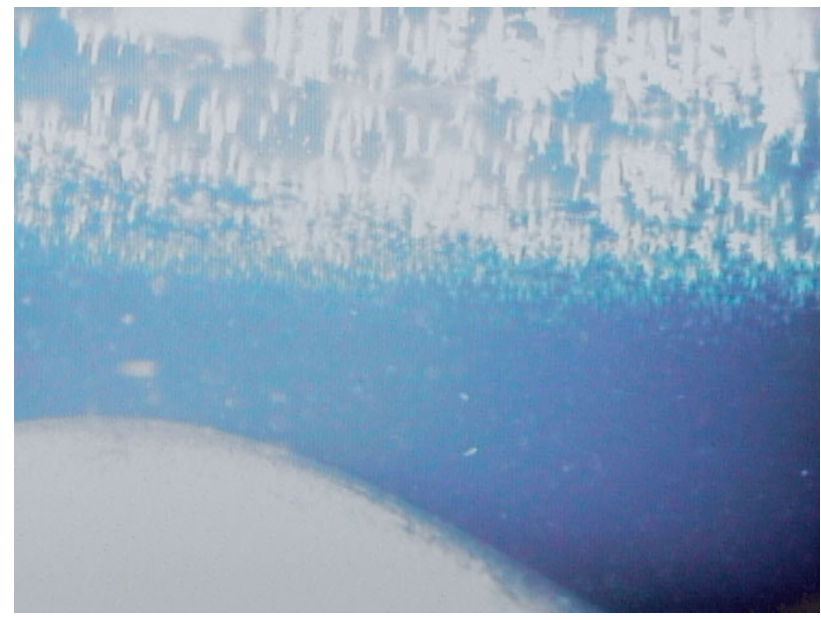

(e)

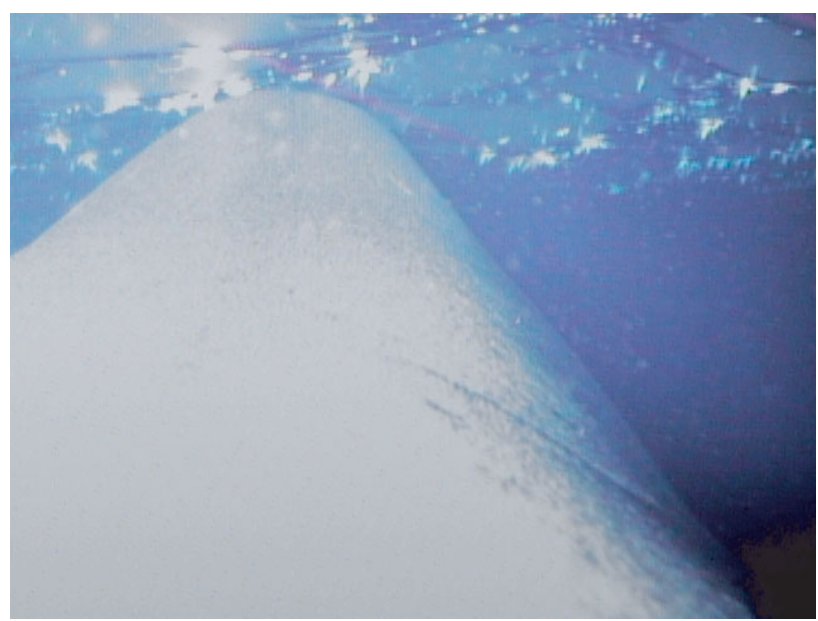

(b)

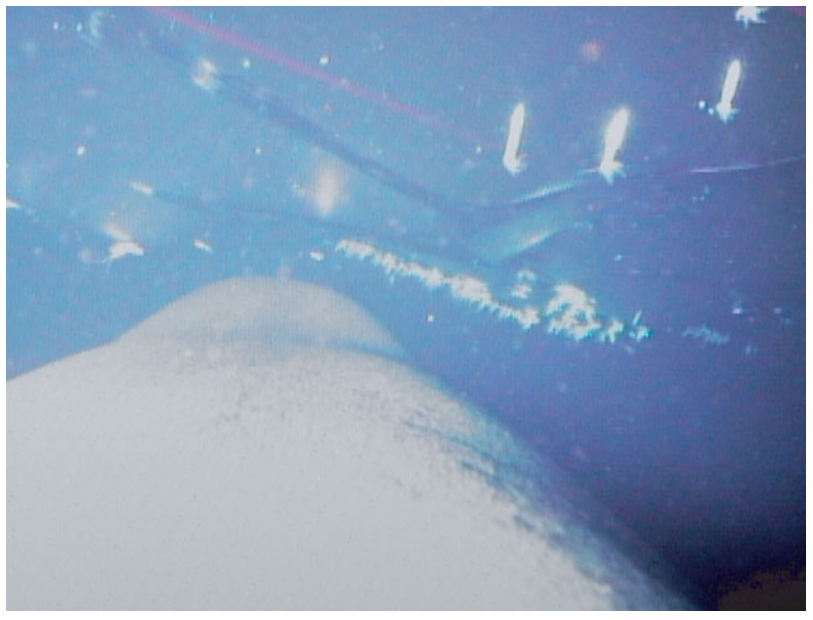

(d)

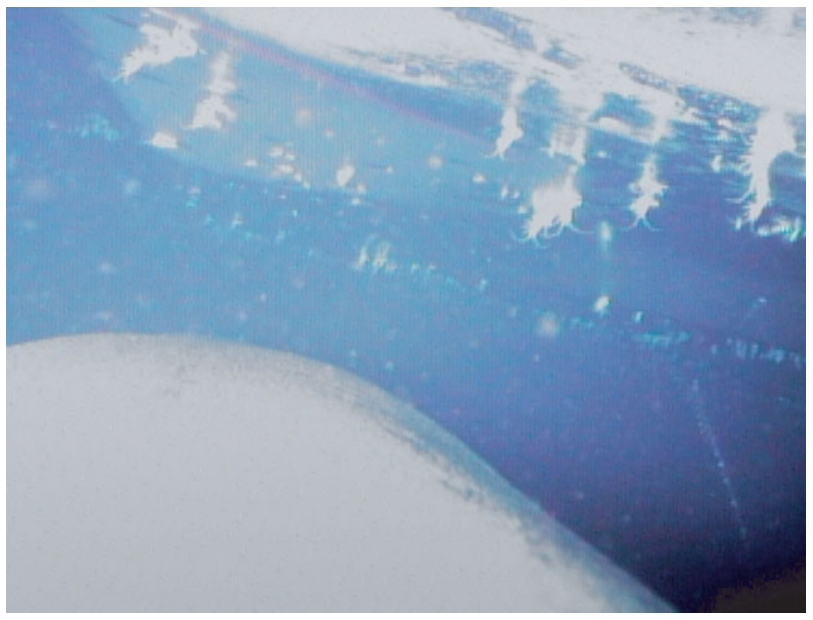

Fig. 1. Images taken with the seal borne, digital still camera system, showing the underwater surface-structure of an Antarctic ice shelf (looking forward over the seal's back). (a) Surface of the ice shelf edge, along which the seal was descending. Depth: $97 \mathrm{~m}$. (b) Invertebrates on the underside of the ice shelf, possibly cnidarians with tubular bodies ending in a crown of tentacles. Depth: 150 m. (c) Dense aggregation of the invertebrates shown in (b). Depth: 148 m. (d) Crustaceans, possibly isopods (Antarcturus sp.), hanging down from the ice shelf, with long paired antennae and what appear to be legs in filter-feeding mode. Depth: $161 \mathrm{~m}$. (e) A seal stretching its neck towards the ice shelf, possibly to capture prey. Depth: $151 \mathrm{~m}$ 
and A. Clarke and T. Iwami for providing information on marine invertebrates. The field experiments conformed to the provisions of the Protocol on Environmental Protection to the Antarctic Treaty. The applied immobilization and deployment techniques were permitted by the Federal Environmental Agency of Germany (UBA: Az. I 2.4-94003-3/121). This work was funded by the Japan Society for the Promotion of Science (13460082, 14405027 and 15255003), JSPS Research Fellowships for Young Scientists (Y.W.), Ministry of Education, Culture, Sports, Science and Technology, Japan (12NP0201) and the Alfred-Wegener-Institut für Polar- und Meeresforschung, Germany.

\section{LITERATURE CITED}

Arntz WE, Brey T, Gallardo VA (1994) Antarctic zoobenthos. Oceanogr Mar Biol Annu Rev 32:241-304

Bornemann H, Mohr E, Plötz J, Krause G (1998) The tide as zeitgeber for Weddell seals. Polar Biol 20:396-403

Brierley AS, Fernandes PG, Brandon MA, Armstrong F and 8 others (2002) Antarctic krill under sea ice: Elevated abundance in a narrow band just south of ice edge. Science 295:1890-1892

Davis RW, Fuiman LA, Williams TM, Collier SO, Hagey WP, Kanatous SB, Kohin S, Horning M (1999) Hunting behavior of a marine mammal beneath the Antarctic fast ice. Science 283:993-995

Davis RW, Fuiman LA, Williams TM, Horning M, Hagey W (2003) Classification of Weddell seal dives based on 3-dimensional movements and video-recorded observations. Mar Ecol Prog Ser 264:109-122

Doake CSM, Vaughan DG (1991) Rapid disintegration of the Wordie Ice Shelf in response to atmospheric warming. Nature 350:328-330

Fuiman LA, Davis RW, Williams TM (2002) Behavior of midwater fishes under the Antarctic ice: observations by a predator. Mar Biol 140:815-822

Hooker SK, Boyd IL (2003) Salinity sensors on seals: use of marine predators to carry CTD data loggers. Deep-Sea Res I 50:927-939

Hooker SK, Boyd IL, Jessopp M, Cox O, Blackwell J, Boveng

Editorial responsibility: Kenneth Sherman (Contributing

Editor), Narragansett, Rhode Island, USA
PL, Bengtson JL (2002) Monitoring the prey-field of marine predators: combining digital imaging with datalogging tags. Mar Mamm Sci 18:680-697

Mitani Y, Sato K, Ito S, Cameron MF, Siniff DB, Naito Y (2003) A method for reconstructing three-dimensional dive profiles of marine mammals using geomagnetic intensity data: results from two lactating Weddell seals. Polar Biol 26:311-317

Mitani Y, Watanabe Y, Sato K, Cameron MF, Naito Y (2004) 3D diving behavior of Weddell seals with respect to prey accessibility and abundance. Mar Ecol Prog Ser 281:275-281

Plötz J, Bornemann H, Knust R, Schröder A, Bester M (2001) Foraging behaviour of Weddell seals, and its ecological implications. Polar Biol 24:901-909

Ponganis PJ, Van Dam RP, Marshall G, Knower T, Levenson DH (2000) Sub-ice foraging behavior of emperor penguins. J Exp Biol 203:3275-3278

Rott H, Skvarca P, Nagler T (1996) Rapid collapse of northern Larsen Ice Shelf, Antarctica. Science 271:788-792

Sato K, Mitani Y, Cameron MF, Siniff DB, Watanabe Y, Naito $Y$ (2002) Deep foraging dives in relation to the energy depletion of Weddell seal (Leptonychotes weddellii) mothers during lactation. Polar Biol 25:696-702

Shepherd A, Wingham D, Payne T, Skvarca P (2003) Larsen Ice Shelf has progressively thinned. Science 302:856-859

Swithinbank C (1988) Satellite image atlas of glaciers of the world: Antarctica. United States Geological Survey, Washington, DC

Takahashi A, Sato K, Naito Y, Dunn MJ, Trathan PN, Croxall JP (2004) Penguin-mounted cameras glimpse underwater group behaviour. Proc R Soc Lond B (Suppl) 271: S281-S282

Vaughan DG, Doake CSM (1996) Recent atmospheric warming and retreat of ice shelves on the Antarctic Peninsula. Nature 379:328-331

Watanabe Y, Mitani Y, Sato K, Cameron MF, Naito Y (2003) Dive depths of Weddell seals in relation to vertical prey distribution as estimated by image data. Mar Ecol Prog Ser 252:283-288

Watanabe Y, Baranov EA, Sato K, Naito Y, Miyazaki N (2004) Foraging tactics of Baikal seals differ between day and night. Mar Ecol Prog Ser 279:283-289

Submitted: February 2, 2005; Accepted: September 26, 2005 Proofs received from author(s): March 15, 2006 